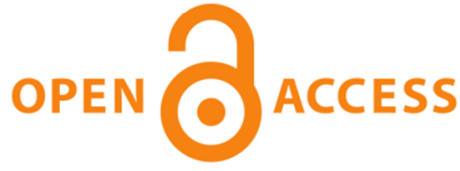

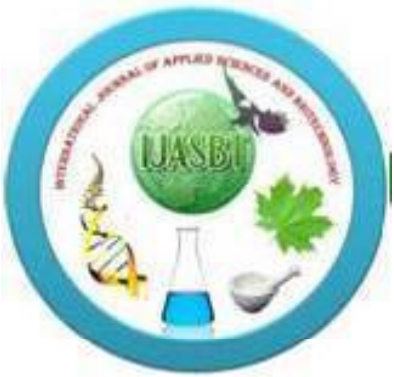 \\ International Journal of Applied Sciences and Biotechnology
}

\author{
A Rapid Publishing Journal
}

ISSN 2091-2609

\section{Indexing and Abstracting}

CrossRef, Google Scholar, Global Impact Factor, Genamics, Index Copernicus, Directory of Open Access Journals, WorldCat, Electronic Journals Library (EZB), Universitätsbibliothek Leipzig, Hamburg University, UTS (University of Technology, Sydney): Library, International Society of Universal Research in Sciences (EyeSource), Journal Seeker, WZB, Socolar, BioRes, Indian Science, Jadoun Science, JourInformatics, Journal Directory, JournalTOCs, Academic Journals Database, Journal Quality Evaluation Report, PDOAJ, Science Central, Journal Impact Factor, NewJour, Open Science Directory, Directory of Research Journals Indexing, Open Access Library, International Impact Factor Services, SciSeek, Cabell's Directories, Scientific Indexing Services, CiteFactor, UniSA Library, InfoBase Index, Infomine, Getinfo, Open Academic Journals Index, HINARI, etc.

\section{CODEN (Chemical Abstract Services, USA): IJASKD}
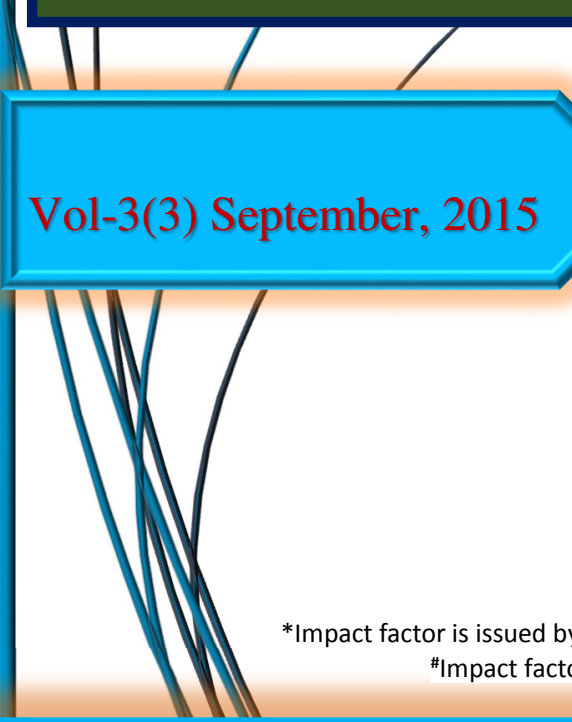

\section{Available online at:}

\author{
http://www.ijasbt.org
}

$\&$

http://www.nepjol.info/index.php/IJASBT/index

Impact factor*: $\mathbf{1 . 4 2 2}$

Scientific Journal Impact factor ${ }^{\#}: 3.419$

Index Copernicus Value: 6.02

IBI Factor 2015**: 4.19 
Research Article

\title{
DNA EXTRACTION TECHNIQUE FOR DIFFERENT RICE VARIETIES GROWN IN SRI LANKA
}

\author{
Ranganathan Kapilan \\ Department of Botany, University of Jaffna, Jaffna, Sri Lanka. \\ Email: ranganat@ualberta.ca / rskap@jfn.ac.lk
}

\begin{abstract}
Extraction of DNA is very important nowadays in bio-molecular researches. Extracted DNA should be purified and the quality of DNA should also be very high. The objective of the study was to develop a simple efficient method to isolate DNA from the rice varieties in an open laboratory environment, and to eliminate the usage of expensive chemicals and tools. The DNA extraction methods developed by the DNeasy plant kit method supplied by QIAGEN, Cheng et al., Doyle et al. and Michiels et al. were applied to five different rice varieties grown in different parts of Sri Lanka. Based on the quantity and quality of the extracted DNA tested by measuring the absorbance of DNA at $260 \mathrm{~nm}$ using Nanodrop ${ }^{\circledR}$ ND-1000 spectrophotometer and measuring the ratio of $\mathrm{A}_{260}$ / $\mathrm{A}_{280}$ and gel running on agarose, the efficiency of the extraction method chosen varied among rice varieties. Among the methods used, the methods introduced by DNeasy plant kit method supplied by QIAGEN and Cheng et al, yielded good and amplifiable quality DNA with satisfactory concentration for all the rice varieties tested. Therefore the modified method of Cheng et al, 1987 could be used to extract DNA from rice varieties instead of the commercially available expensive and hazardous DNeasy plant kit method supplied by QIAGEN.
\end{abstract}

Key words: DNA extraction; Rice; DNeasy plant kit; Nanodrop; ratio of A260 / A280

\section{Introduction}

It is very important to extract pure, intact, and high-quality DNA for molecular biology studies (Tan and Yiap, 2009). Generally extraction of DNA from plants is usually very critical because of the excessive contamination by secondary metabolites and the steps involved (Sangwan $e t$ al., 1998). The DNA extraction methods are modified to improve the quality and quantity of DNA. Therefore the protocols differ among plant species and plant tissues and this may be due to the presence of secondary metabolites, structure of the plant tissues (Peterson et al., 1997). The efficient DNA extraction method for diverse plant varieties is needed to generate pure DNA samples with good quality and satisfactory quantity (Peterson et al., 1997; Porebski et al., 1997). Some plants develop stress resistance by synthesizing higher amount of polysaccharides, polyphenols, alkaloids and flavanoids like secondary metabolites that could affect the DNA extraction (Cheng et al., 2003).DNA degradation or shearing of DNA are major issues uncounted during the purification of most of the plant DNA and endonucleases directly or indirectly interfere with the DNA causing the damage (Weishing et al., 1995). Polysaccharides inhibit the activities of the Taq polymerase and restriction endonucleases (Michiels et al., 2003). The presence of polysaccharides in the DNA sample is identified by the formation of the viscous solution (Fang et al., 1992). The oxidized form of polyphenols covalently binds to DNA giving a brown colour complex and reduces the life of DNA (Xu et al., 2004).Apart from the traditional extraction approaches, diverse commercial kits are used to extract genomic DNA from plants with efficient quality (Pandey et al., 1996). The chemicals used in the kits are mostly toxic, hazardous, expensive, and require special containment facilities to maximize personnel safety and minimize environmental concerns. However, the convenience provided by these methods may be cost prohibitive when considering experiments with limited financial resources. Attempts are made to eliminate the use of hazardous chemicals, expensive kits, equipment, and labor-intensive steps for high throughput DNA extraction. Demerits of these methods are limited shelf life, low purity, low recovery, and poor amplification (Kapilan, 2015a; Doyle and Doyle, 1987). The study was aimed to develop a simple efficient method to isolate DNA from the rice varieties in an open laboratory environment, and to eliminate the usage of expensive chemicals and tools.

\section{Materials and Methods}

\section{Plant materials}

Fresh young leaves( $2^{\text {nd }}$ and $3^{\text {rd }}$ fully expanded healthy leaves from top) from five different rice plant varieties belong to Oryzae sativa (L) such as Mooddaikaruppan, H4, 
Periyavellai, 500-1 and IR8were used as DNA sources. They were harvested in the Jaffna district (300 M to 1200 $\mathrm{M}$ above mean sea level), and brought to the laboratory in ice bags. For each method used as a first step the leaf tissue was fine ground in liquid nitrogen using sterile mortar and pestle and resulting powder was kept in a sterile tube at $20^{\circ} \mathrm{C}$ until use.

\section{Extraction methods}

Genomic DNA extraction methods demonstrated by (1). DNA extraction Kit (QIAGEN) (2). Cheng et al. 1987 (3). Doyle and Doyle, 1987 and (4). Michiels et al., 2003 were employed for the comparison. There were three replicates for each rice variety for each method and experiments were repeated.

\section{DNA quantity and purity confirmation}

Genomic DNA from the leaf samples were quantified by measuring the absorbance at $260 \mathrm{~nm}$ using Nanodrop ${ }^{\circledR}$ ND1000 spectrophotometer. The ratio $\left(\mathrm{A}_{260 / 280} \mathrm{~nm}\right)$ was calculated to determine the purity of the DNA sample to find out whether it was contaminated with protein or not.

\section{Gel running}

The size, purity, integrity and amplifiable quality of DNA were determined by running $1 \mu \mathrm{L}$ of total DNA from each sample on a $1 \%$ agarose gel $(0.5 \mathrm{X}$ TBE) for 45 minutes with $60 \mathrm{~V}$ current and with $0.5 \mathrm{X}$ TBE buffer, and visualized by SYBR safe.

\section{Results and Discussion}

\section{Quantity of DNA}

The quantity of DNA extracted by four different methods, significantly varied among the five rice varieties tested. Fresh leaves of H4, yielded maximum amount of DNA with overall mean of $2750 \mu \mathrm{g} / \mathrm{g}$ fresh leaf followed by IR8 with the overall mean of $2460 \mu \mathrm{g} / \mathrm{g}$ fresh leaf. There was not much variation in quantities of DNA extracted from leaves of other three varieties. The method of Cheng et al., 1987 yielded maximum amount of DNA with overall mean of $2450 \mu \mathrm{g} / \mathrm{g}$ fresh leaf followed by the DNA extraction kit $(2550 \mu \mathrm{g} / \mathrm{g}$ fresh leaf). DNA quantity was comparatively minimum in the method of Doyle and Doyle (Doyle and Doyle, 1987) with overall mean of $2150 \mu \mathrm{g} / \mathrm{g}$ fresh leaf (Fig. 1).
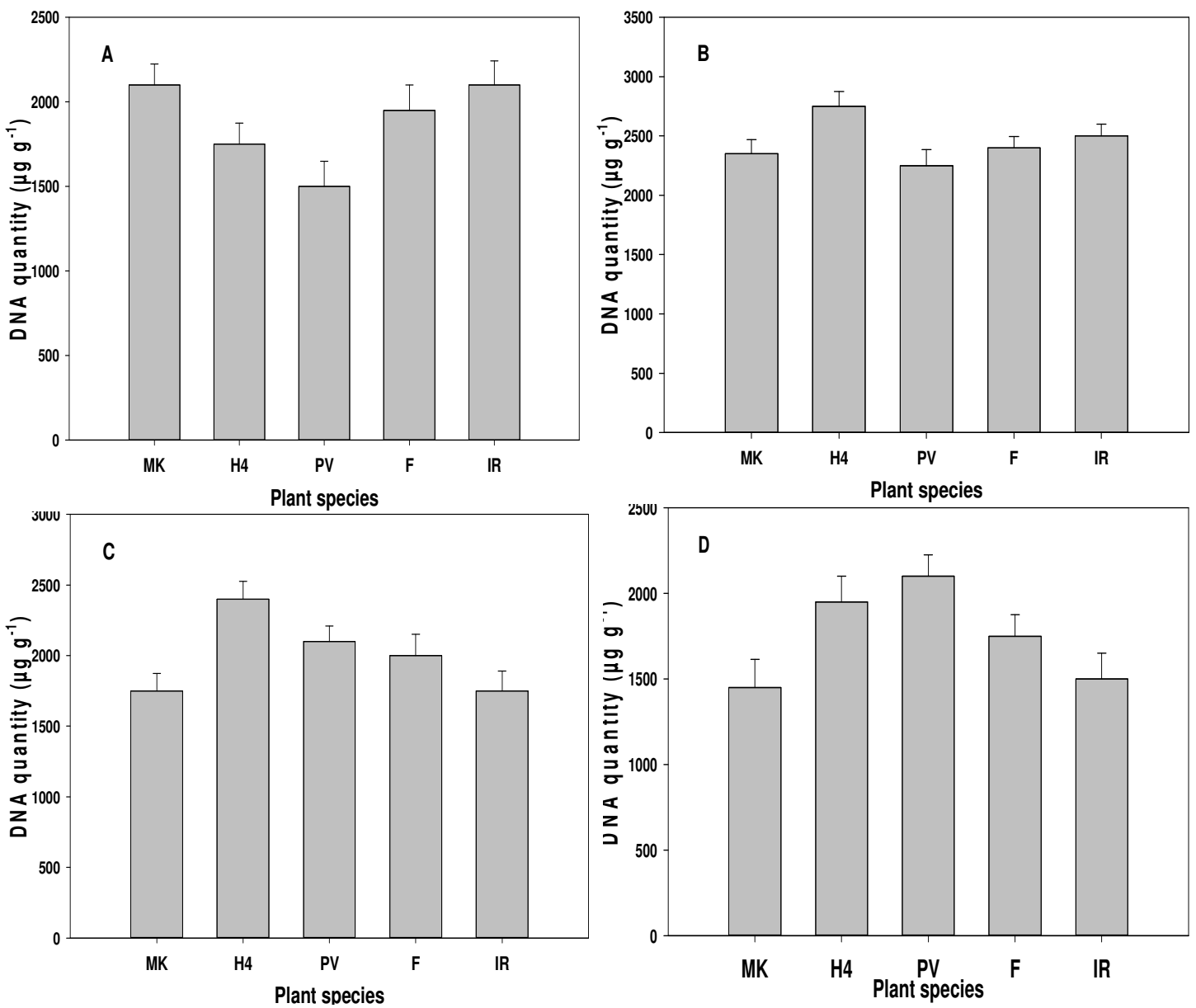

Fig. 1: Extracted DNA quantity means of different rice varieties of Sri Lanka (Letters MK, H4, PV, F and IR denotes Mooddaikaruppan, H4, Periyavellai, 500-1 and IR8. A - Doyle method, B - Kit method, C- Cheng method \& D Michiel method). 


\section{Quality of DNA}

Among the extraction methods tested, DNA extraction Kit (QIAGEN) method, Chang method and Doyle and Doyle method yielded DNA of highest quality with the absorbance ratio (A260:A280) of 1.72,1.74and 1.69 respectively. Doyle and Doyle method resulted in the lowest quality of DNA with absorbance ratio of 1.52 (Fig. 2). However, with this method, except for IR8 and Periya Vellai that yielded DNA with satisfactory quality, other varieties yielded high quality DNA with absorbance ratio of about1.7.Amongthe rice varieties, $\mathrm{H} 4$ consistently yielded DNA with high purity ratio (A260:A280 $\geq$ 1.8)with all the four methods investigated. Gel running of samples from all the plant species using all the four methods showed considerable amount of amplifiable quality DNA except Periya vellai with Doyle method. The present study showed that there was variation in time required for different DNA extraction methods. The method of Cheng et al., 1987 consisted of comparatively few steps for the completion of the entire extraction process and was the most rapid extraction method requiring less than seven hours. On the contrary, the method of Bousquet et al., Doyle and Doyle, 1987 and Michiels et al., 2003 involved several time consuming extraction steps and took more than 16 hours to finish the entire processes. The protocols differ among rice varieties and plant species and the tissues and this may be due to the production of secondary metabolites and complicated plant structures (Peterson et al., 1997). DNA isolated by Chang method and Kit method yielded, reproducible and consistent amplification products proving its compatibility for PCR applications using SSR primer. Long-tail surfactants such as CTAB in the Doyle method change the conformation in the DNA from "random coil" to "compact globule", facilitating the DNA precipitation efficiently. Phenols and related compounds are very good oxidizing agents and bind covalently to the extracted DNA. This will make the DNA useless for most of molecular manipulations (Doyle and Doyle, 1987; Padmalatha and Prasad, 2006).
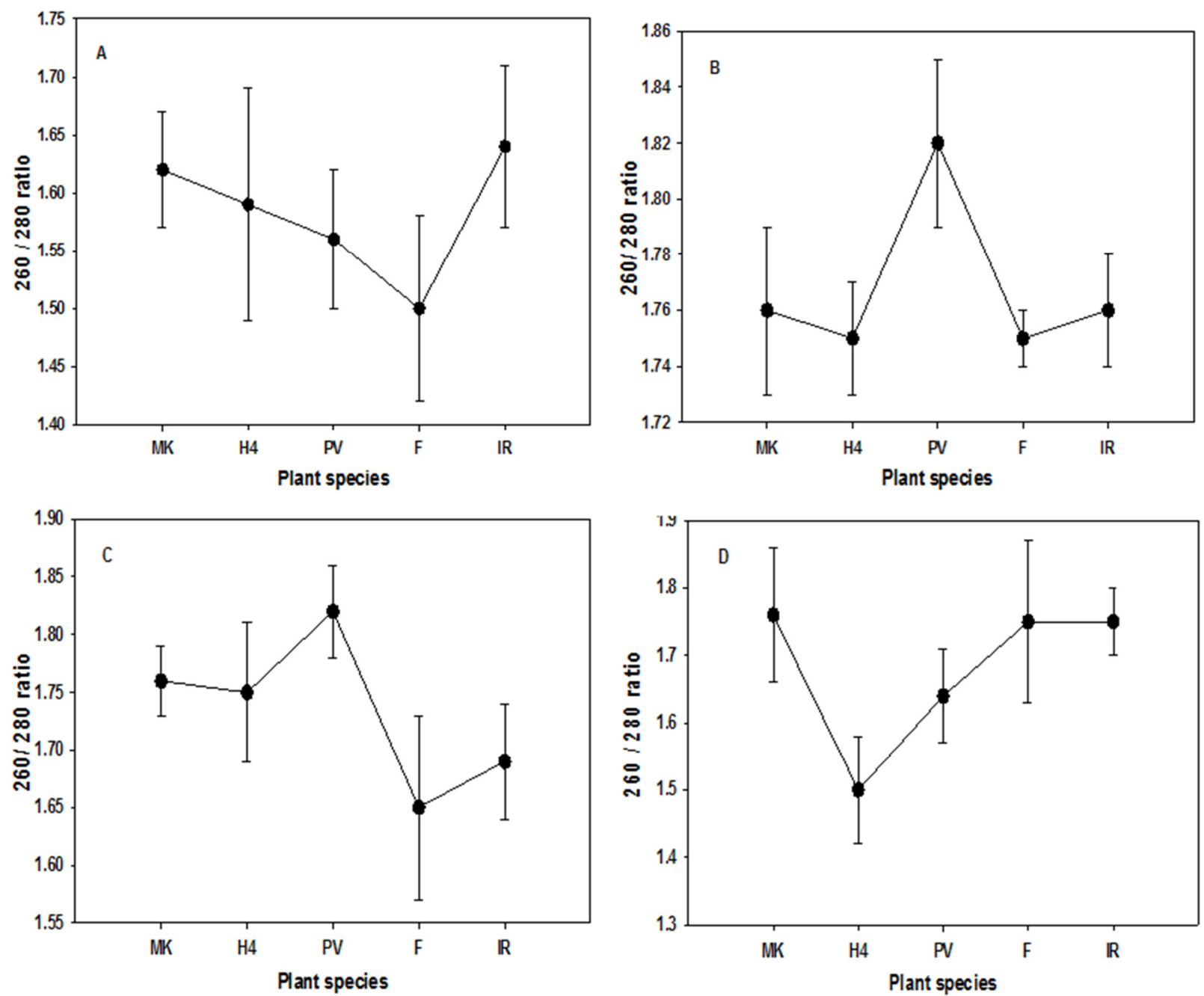

Fig. 2: Means of the 260/280 ratio for DNA obtained for different rice varieties (Letters MK, H4, PV, F and IR denotes Mooddaikaruppan, H4, Periyavellai, 500-1 and IR8. A - Doyle method, B - Kit method, C- Cheng method \& D - Michiels method). 
$\begin{array}{llllllllllllllllll}\text { MO } & \text { H4 } & \text { PV } & \text { F1 } & \text { IR } & \text { MO H4 PV F1 } & \text { IR } & \text { MO H4 PV F1 IR MO H4 PV F1 IR } & \text { M }\end{array}$
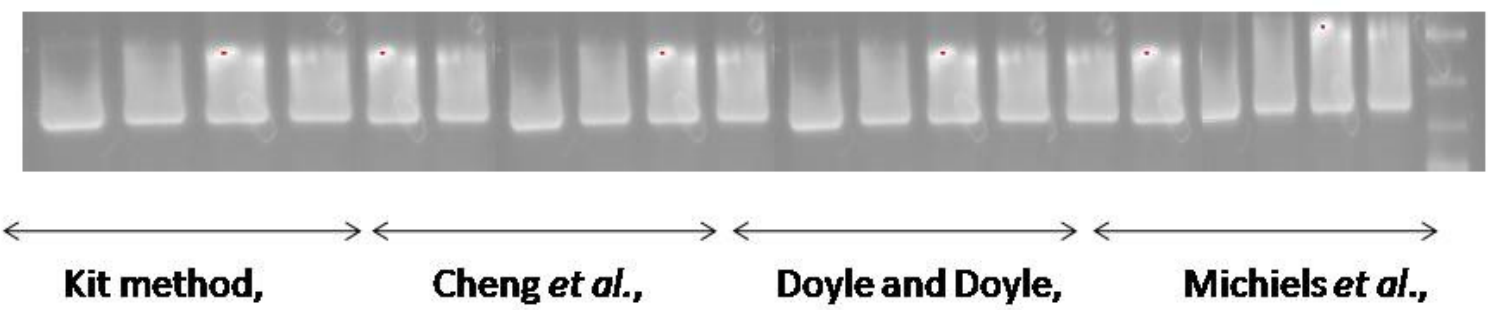

Fig 3: Bands of DNA on the $1 \%$ agarose gel with $0.5 \mathrm{X}$ TBE buffer after visualization with SYBR safe. M- Marker Other alphabets indicate the first letter of the generic and species names of the plants used (Letters MK, H4, PV, F and IR denotes Mooddaikaruppan, H4, Periyavellai, 500-1 and IR8. M - 1 kb DNA ladder)

\section{Amplification quality DNA}

Gel running of samples from all the rice varieties using all the four DNA extraction methods showed satisfactory amplifiable quality of DNA (Fig 3). This study showed that there was variation in time required for different DNA extraction methods. The method of Cheng et al., 1987 and DNA extraction Kit (QIAGEN) method both consisted of comparatively few steps for the completion of the entire extraction process (less than seven hours). Variation in quality of DNA can be due to the genetics, structural and biochemical variation among leaf samples of different plant species, variation in types of buffers used for extraction and the difference in the extraction with varying parameters and chemicals (Kapilan, 2015b).

\section{Conclusion}

Among the methods used, the method introduced by DNeasy plant kit method supplied by QIAGEN and Cheng et al, yielded good and amplifiable quality DNA with satisfactory concentrations for all the rice varieties tested. This modified method of Cheng et al, 1987 could also be used to extract DNA from other plants after testing the quality of DNA, instead of the commercially available expensive and hazardous DNeasy plant kit method supplied by QIAGEN.

\section{Acknowledgement}

The author thanks Dr. T. Mohan of University of Alberta for providing the QIAGEN kit facilities and support.

\section{References}

Cheng YJ Goo WWU Hua-Lin YI Pang XM and Deng X (2003) An efficient protocol for genomic DNA extraction from citrus species. Plant Molecular Biology Reporter. 21(2):177-178. DOI: 10.1007/BF02774246

Doyle JJ Doyle JL (1987) A rapid DNA isolation procedure for small quantities of fresh leaf tissue. Photochemical Bulletin. 19:11-15.

Fang G Hammar S and Grumet R (1992) A quick and inexpensive method for removing polysaccharides from plant genomic DNA," BioTechniques. 13(1):52-56.
Kapilan R (2015a) Efficient DNA Extraction Technique from Leave Tissues of Some Important Tropical Plant Species. Journal of progressive research in biology. 1(1):29-32.

Kapilan R (2015b) Comparison of the efficiency of the DNA extraction methods of some selected plant species. Sch. Acad. J. Biosci. 3(7):611-615.

Michiels A Van Den Ende W Tucker K Van Riet L and Van Laere A (2003) Extraction of high-quality genomic DNA from latex-containing plants. Analytical Biochemistry. 315:8589. DOI: $10.1016 / \mathrm{S} 0003-2697(02) 00665-6$

Padmalatha K Prasad MNV (2006) Optimization of DNA isolation and PCR protocol for RAPD analysis of selected medicinal and aromatic plants of conservation concern from Peninsular India. Afr J Biotechnol. 5(3):230-234.

Pandey RN Adams RP and Flournoy (1996) Inhibition of random amplified polymorphic DNAs (RAPDs) by plant polysaccharides. Plant Molecular Biology Reporter. 14:17-22. DOI: 10.1007/BF02671898

Peterson DG Boehm KS, and Stack SM (1997) .Isolation of milligram quantities of nuclear DNA from tomato (Lycopersicon esculentum), a plant containing high levels of polyphenolic compounds. Plant Molecular Biology Reporter. 15(2):148-153. DOI: 10.1007/BF02812265

Porebski S Bailey LG and Baum BR, (1997) Modification of a CTAB DNA extraction protocol for plants containing high polysaccharide and polyphenol components. Plant Molecular Biology Reporter. 15(1):8-15. DOI: 10.1007/BF02772108

Sangwan NS Sangwan RS and Kumar S (1998) Isolation of genomic DNA from the antimalarial plant Artemisia annua.Plant Molecular Biology Reporter, 16 (4):19. DOI: 10.1023/A:1007545102889

Tan SC and Yiap BC (2009) DNA, RNA, and protein extraction: the past and the present. Journal of Biomedicine and Biotechnology. 10 ID 574398. DOI: 10.1155/2009/574398

Weishing Nybom K Wolff H and Meyer W (1995) DNA isolation and purification in DNA Fingerprinting in Plants and Fungi. pp 44-59. CRC Press, Boca Raton, Fla, USA.

Xu Q Wen X and Deng X (2004) A simple protocol for isolating genomic DNA from Chestnut Rose (Rosa roxburghii tratt) for RFLP and PCR analyses. Plant Molecular Biology Reporter. 301-302. DOI: 10.1007/BF02773140 